\title{
Cardiomyocyte differentiation of mesenchymal stem cells from bone marrow: new regulators and its implications
}

\author{
Xiaofei Guo ${ }^{1}$, Yan Bai ${ }^{1}$, Li Zhang ${ }^{1}$, Bo Zhang ${ }^{1}$, Naufal Zagidullin², Katherine Carvalho ${ }^{3}$, Zhimin Du \\ and Benzhi Cai ${ }^{1 *}$ (ID
}

\begin{abstract}
In the past years, cardiac mortality has decreased, but cardiac diseases are still responsible for millions of deaths every year worldwide. Bone-marrow mesenchymal stem cells (BMSCs) transplantation may be a promising therapeutic strategy because of its capacity to differentiate into cardiac cells. Current research indicates that chemical substances, microRNAs, and cytokines have biological functions that regulate the cardiomyocytes differentiation of BMSCs. In this review, we chiefly summarize the regulatory factors that induce BMSCs to differentiate into cardiomyocytes.
\end{abstract}

Keywords: Bone marrow-derived mesenchymal stem cells, Cardiomyocytes, Differentiation, microRNAs, Cytokines, Microenvironment

\section{Background}

Cardiac diseases remain the leading cause of death worldwide, both in developed and developing countries. Cardiac diseases can progress rapidly, such as acute myocardial infarction (AMI), or progress slowly, such as cardiac remodeling, which is characterized by cardiac hypertrophy and myocardial fibrosis that can eventually lead to heart failure. Although, a variety of measures have been put into clinical practice and achieved certain curative effects, the poor prognosis and irreversible

\footnotetext{
*Correspondence: caibz@ems.hrbmu.edu.cn

${ }^{1}$ Department of Pharmacy, the Second Affiliated Hospital of Harbin Medical University, No. 246 Xuefu Road, Harbin, Heilongjiang Province 150081, People's Republic of China

Full list of author information is available at the end of the article
}

pathology of cardiac remodeling still limit their therapeutic effect for cardiac diseases.

Nowadays, significant advances have been made in the field of cardiac diseases and stem cell transplantation-based therapies have emerged as a promising therapeutic tool for improving cardiac regeneration and function [1-3]. In addition, pluripotent stem cells, including embryonic stem (ES) cells, induced pluripotent stem (iPS) cells, and multipotent/unipotent stem cells like bone marrow-derived mesenchymal stem cells (BMSCs) can be differentiated into cardiomyocytes in vitro [4-7]. However, the ideal source of stem cells remains elusive, with the drawbacks of limited engraftments and differentiation potential, ethical issues, and immunologic incompatibility. Of these stem cell types, BMSCs have several advantages of easy availability, powerful capacity of proliferation, immune modulatory properties, and migration to damaged tissues [8]. BMSC transplantation is considered a promising cardiac disease strategy due to differentiation [9-11]. Many efforts have been proved to facilitate differentiation of BMSCs into cardiomyocytes, such as chemical substances, microRNAs, and cytokines, or alter culture intermediaries [12-14].

\section{Chemicals}

5-Azacytidine (5-aza) is an important chemical inducer that can induce BMSCs to differentiate into cardiomyocytes in murine samples [15]. Antonitsis et al. also found that 5-aza could stimulate BMSCs to differentiate into cardiomyocytes via random demethylation of DNA in the human body $[16,17]$. Although 5-aza has been extensively used in stem cell differentiation, the carcinogenicity of 5-aza still blocks therapeutic applications [18] so other alternative options for BMSCs to differentiate into cardiomyocytes are imperative. 


\section{MicroRNAs}

MicroRNAs (miRNAs) are a class of noncoding RNAs about 22 nucleotides long that can act as negative regulators of gene expression by binding to the 3' UTR of mRNAs [19]. Previous studies have confirmed that miRNAs can play a significant role in cell development, differentiation, proliferation, and apoptosis [20]. Studies have also demonstrated that miRNAs can regulate differentiation of BMSCs [21, 22]. However, whether miRNAs could regulate cardiomyocyte differentiation of BMSCs is still little known.

Zhao et al.'s [23] study reveals that miR-1a could promote the differentiation of BMSCs into myocardial cells. Their results show that BMSCs could differentiate into myocardial cells in special conditioned medium, but will be efficient when overexpressing miR-1a. As an in-depth study, they demonstrate that Delta-like 1 (Dll-1) is the key inhibitor of myocardium gene expression during myocardium differentiation and that miR-1a can reduce the expression of Dll-1 by targeting the 3' UTR, leading to the dramatic upregulation of myocardium gene protein.

Cai et al. [24] show that BMSCs are transformed into cardiomyocytes by coculture with cardiomyocytes, and cardiac-specific markers such as atrial natriuretic peptide (ANP), cardiac troponin $\mathrm{T}(\mathrm{cTnT})$, and $\alpha$-myosin heavy chain $(\alpha-\mathrm{MHC})$ are detected. miRNA assay indicates that the level of miR-124 is significantly downregulated during cardiomyocte differentiation of BMSCs. The authors then performed functional experiments on the acquisition or loss of miR-124 and find that overexpression of miR-124 would inhibit cardiomyocyte differentiation of BMSCs. By further study into the molecular mechanism of this progress, the authors demonstrate that miR-124. exerts a negative effect on myogenic differentiation of BMSCs via targeting signal transducers and activators of transcription 3 (STAT3) [24].

Shen et al. [25] find the expression of miR1-2 is significantly increased after 5-aza treatment. In order to clear the role of miR1-2 in modulating cardiomyocyte differentiation, miR1-2 mimics are transferred into BMSCs, and these cells are induced to differentiate into cardiomyocytes by the expression of cardiac-specific genes GATA binding protein 4 (GATA4), cardiac troponin I (cTnI), and Homeobox protein 2.5 (Nkx2.5). Further study shows that miR1-2 could activate the Wnt/ $\beta$-catenin signaling pathway, whereas BMSCs pretreated with Wnt/ $\beta$-catenin signaling inhibitor LGK-974 can weaken the differentiation of BMSCs into cardiomyocytes. To sum up, miR1-2 could regulate the differentiation of BMSCs into cardiomyocytes via the Wnt/ $\beta$-catenin signaling pathway [25].

miRNAs could regulate gene expression and the cardiomyocyte development and differentiation of stem cells [26], including BMSCs. For instance, miR-23b inhibits the osteogenic differentiation of BMSCs via targeting Runx 2 during treatment with TNF- $\alpha$ [27]. The miR-1/133 family has a high level in the heart, but they have opposing effects: miR-1 promotes and miR-133 blocks differentiation into cardiac cells. A previous study has shown that Jagged 1 protein could activate Notch signal and promote the differentiation of BMSCs into cardiomyocytes in vitro and in vivo [28], and miR-1 could promote myocardial differentiation in stem cells via targeting Dll-1, a Notch ligand expressed in ES cells [29]. The Wnt signaling pathway has an essential role in cardiomyocyte development and $\beta$-catenin could promote the occurrence of the heart in Drosophila [30]. The Wnt signaling pathway also regulates the proliferation and differentiation of BMSCs [31]. miR-29c-3p is significantly upregulated and could regulate the osteoblast differentiation of rat BMSCs by targeting Dishevelled 2, a key mediator of the $\mathrm{Wnt} / \beta$-catenin signaling pathway, in a hyperlipidemia environment [32]. Therefore, the increasing in miR-124 level is considered to be an important trigger of the transition from proliferation to neural differentiation [33]. STAT3 has a significant role in self-renewal, differentiation, and paracrine activation of BMSCs [7, 34]. Activation of STAT3 has been reported that could enhance the differentiation of transplanted BMSCs and produce better function of infarcted myocardium. miR-124 regulates the activation of STAT3 and in turn affects myogenic differentiation of BMSCs.

The miRNAs mimics group have a lower apopotic rate than the 5-aza group, indicating miRNAs are less cytotoxic. BMSCs treated with miRNAs express cardiacspecific genes but these cells are still short of the morphology of cardiomyocytes, indicating that further investigation needs to be done. Long noncoding RNAs have been shown to play important roles in multiple physiological processes. Nowadays, lncRNA H19 could mediate osteogenesis differentiation of BMSCs by sponging miR-138 [35]. This might be a new strategy to induce cardiomyocyte differentiation of BMSCs through miRNAs.

\section{Cytokines}

\section{Growth factor}

Growth factors such as epidermal growth factor, plateletderived growth factor, fibroblast growth factor, nerve growth factor, and insulin-like growth factor are cytokines that can affect cell growth and differentiation. Whether it can regulate the differentiation of cardiomyocytes in BMSCs needs to be further explored.

\section{Insulin-like growth factor-1}

Insulin-like growth factor-1 (IGF-1) plays an important role in the regulation of cell proliferation, apoptosis, and tumorigenicity [36-38]. Growing evidence indicates that BMSCs have the potential to differentiate into 
cardiomyocyte-like cells (CLCs) which have the capacity for contractility and can express the cardiac-specific gene [39-41]. Whether IGF-1 could participate in cardiomyocytes differentiation of BMSCS, more experiments need to be done.

Transplanted BMSCs need a feasible microenvironment to differentiate into cardiomyocytes in the ischemic area [42]. In-vitro experiments suggest that HGF has a significant role in promoting myocardial differentiation of BMSCs, but lacking the ability to proliferate and inhibit apotpsis. However, IGF-1 could significantly supply the gap of HGF. Research has tried to investigate the effect of combination of two factors in AMI therapy [43], and the combination of IGF-1 and HGF could promote the cardioprotective effects of adipose-derived stem cells [44]. Zhang et al. [45] find that a combination of HGF and IGF-1 could inhibit BMSC apoptosis and increase angiogenesis. To further investigate whether HGF and IGF-1 could induce the cardiomyocyte differentiation of BMSCs, immunofluorescence staining, qRT$\mathrm{PCR}$, and western blot analysis are executed. After treatment of BMSCs with HGF and IGF-1, the level of cardiac-specific markers like cardiac troponin $\mathrm{T}$ (cTnT), GATA4, NKx2.5, and Connexin 43 (CX43) are all increased, suggesting that the combination of HGF and IGF-1 could achieve the dual purpose of not only promoting differentiation of BMSCs into cardiomyocytes but also inhibiting apoptosis induced by hypoxia [45]. However, the mechanism is not clear.

IGF-1 can affect cell proliferation, apoptosis, angiogenesis, and cardiac protection, especially the differentiation of stem cells, and a previous study shows that insulinlike growth factor could promote differentiation after transplanting ES cells for myocardial renovation [46]. IGF-1R is the significant individual component, and IGF/IGF-1R can be activated to enhance proliferation and survival of many cells [47]. Gong et al. [48] notice the increased expression of myocardium markers cTnT, cTnI, and phosphorylation IGF-1 receptor (pIGF-1R) after exposing BMSCs to IGF-1. To confirm whether the differentiation of BMSCs into CLCs is induced by IGF-1, BMSCs are treated with IGF-1 and I-OMe AG538, an IGF-1R kinase inhibitor that can block its autophosphorylation. The results show that the expression of $c \operatorname{TnT}$ and cTnI is decreased through the MAPK and PI3K pathways, which are the two major IGF-1R-related intracellular signaling pathways. In conclusion, IGF-1 induces the BMSCs to differentiate into CLCs via IGF-1R [48]. PI3K/Akt is the downstream signaling pathway of IGF-1, and plays a role in cell survival and migration [49], and the MAPK/ERK pathway could modulate the expression of proteins involved in differentiation. Whether the MAPK/ERK pathway participates in the processes of differentiating BMSCs into CLCs needs further research.

\section{Insulin gene enhancer binding protein ISL-1}

Insulin gene enhancer binding protein ISL-1 (Islet-1) is a significant regulator of cardiac development and cardiomyocyte differentiation [50,51], and is also a marker of undifferentiated cardiac progenitors [52]. A previous study verifies that overexpressed Islet-1 in BMSCs could play a critical role in cardiomyocyte differentiation [52]. This is discussed in the context of how Islet-1 carries the differentiation function. Yi et al. [53] find that increasing expression of Islet- 1 by lentiviral vector could promote the differentiation of MSCs into CLCs, and the level of GATA4 is also elevated. Further studies demonstrate that Islet- 1 alters the histone acetylation levels of GATA4 and the DNA methylation levels of GATA4 promoter region through Gen5 and DNMT-1 [53].

Epigenetic modifications, including histone acetylation and DNA methylation, have been demonstrated to serve an important role in cardiomyocyte differentiation of MSCs [54]. Histone acetylation changes the transcriptional activity of chromatin [55], while DNA methylation alters the function of DNA by methylation modifications [56]. Gcn5, the first discovered histone acetyltransferase, mainly modifies nucleosomal histones and free histones [57]. During the process of Islet-1-induced BMSC differentiation into CLCs, the expression of Gcn5 and binding to GATA4 promoter regions are both increased, subsequently enhancing the expression of GATA4 to promote the cardimoycyte differentiation of BMSCs. The main role of DNMT1 is to form DNA methylation, the expression of DNMT1 and binding to GATA4 promoter regions are both decreased in the process of Islet-1 induction. The function of two epigenetic modifications presents a crosscurrent and may regulate the expression of GATA4 reciprocally.

\section{Basic fibroblast growth factor}

Basic fibroblast growth factor (bFGF), one of the heparin binding growth factors, is thought to induce the differentiation of BMSCs into cardiomyocytes during embryogenesis [58], but not cardiomyocyte development [59], indicating that it is necessary for bFGF to combine with other factors in inducing cardiomyocyte differentiation of BMSCs. MSCs isolated from sternal marrow show potential to differentiate into mesodermal lineages, like osteocytes, adipocytes, and chondrocytes, and whether the MSCs have the potential to differentiate into cardiomyocytes is an interest question. Hafez et al. [60] find that bFGF synergizes with hydrocortisone, a steroid drug produced by the adrenal gland, to induce cardiomyocyte differentiation of sternal marrow MSCs. Immunofluorescence analysis and qRT-PCR show that cardiac markers like cTnI, cardiac troponin $\mathrm{C}(\mathrm{cTnC})$, and cardiac intracellular gap junction protein CX43 in bFGF and hydrocortisonetreated BMSCs are upregulated compared with 5-azatreated BMSCs. These data suggest that the combination 
of bFGF and hydrocortisone can not only induce BMSCs to differentiate into cardiomyocytes, but is more efficient than treatment with 5 -aza.

A previous study shows that bFGF could increase migratory activity, engraftment, and therapeutic potency [61]. bFGF could promote new arteriolar formation and LV functional improvements, and is essential in MSC angiogenesis and improving the ischemic surroundings $[62,63]$. It also enhances differentiation of BMSCs for cardiac repair after myocardial infarction [64], suggesting that bFGF is important in cardiac diseases. Hydrocortisone has an important role in the regulation of cardiomyocyte proliferation and differentiation [60]. In the role of maintenance and differentiation of mesodermal cells, bFGF and hydrocortisone may be a good selection to induce cardiomyocyte differentiation. Experiments such as Hafe et al also prove this character [60].

\section{Interleukin}

Cytokines could induce MSCs differentiating into cardiac lineage in the microenvironment. These factors can be derived by autocrine and paracrine signaling. Interleukin, a cytokine, is also vital for regulating cardiac function, development, and pathogenesis. The interleukin- 1 family is a member of proinflammatory cytokines and has been divided into two types: IL- $1 \alpha$ and IL- $1 \beta$, which have biological function in a variety of cells, especially cardiomyocytes [65]. Recent studies have shown that IL-1 $\beta$ plays a critical role in pathogenesis, development, and function of cardiomyocytes in impaired heart [66]. A previous study demonstrates that IL-1 $\beta$ could mediate the neovascularization after myocardial ischemia [67] and cardiac development processes.

Khajeniazi [68] finds that IL-1 $\beta$ has a positive effect on cardiac differentiation as well as 5 -aza in vitro. On pretreatment of BMSCs with IL-1 $\beta$, myocardial marker proteins cTnI, cTnT, CX43, and $\alpha$-cardiac actin are expressed in the process of differentiation. Then, BMSCs are treated with IL- $1 \beta$ and 5 -aza, and the data show that the combination of IL- $1 \beta$ and 5 -aza is more effective than using IL- $1 \beta$ or 5 -aza respectively.

These results show that IL- $1 \beta$ has a potential role in promoting cardiomyocyte differentiation of BMSCs. The expression of Notch ligand Jagged1 can be induced by IL-1 $\beta$ on human dystrophic myogenic cells, which could promote cardiomyocyte differentiation [69]. Based on its pleiotropic features and these data, further studies are needed to delineate whether IL-1 $\beta$ could affect the differentiation process of MSCs into cardiomyocytes. Khajeniazi's [68] result shows that IL- $1 \beta$ could induce differentiation of BMSCs into cardiomyocytes, similar to 5 -aza, but when IL- $1 \beta$ is applied in combination with 5-aza they exert a synergistic impact on cardiomyocyte differentiation. However, the mechanism of IL-1 $\beta$-induced cardiomyocyte differentiation is not clear. Wnt signaling pathway is essential in cardiomyocyte development and it has also been noted that IL- $1 \beta$ has the ability to induce osteogenic differentiation of hMSCs via Wnt-5a/receptor tyrosine kinase-like orphan receptor 2 pathways [70]. It can be suspected that IL-1 $\beta$ might come into play via the Wnt signaling pathway.

\section{TGF- $\beta$ family}

\section{Transforming growth factor $\beta 1$}

TGF- $\beta 1$ belongs to the TGF- $\beta$ family, which can regulate a load of biological processes, including proliferation, survival, differentiation, and migration of various cells $[71,72]$. After treatment with TGF- $\beta 1$, murine BMSCs increase the expression of cardiac-specific markers, such as cTnI, cTnT, $\alpha-\mathrm{MHC}$, and $\alpha$-sarcomeric actin, suggesting that TGF- $\beta 1$ may promote differentiation of BMSCs into cardiomocytes [73]. Further studies report that BMSCs treated with autologous serum and TGF- $\beta 1$ are significantly more sensitive than BMSCs treated with medium supplement containing 10\% FBS and serumfree medium by detecting the expression of cTnT and GATA4, exhibiting a higher rate of proliferation and the capacity to differentiate into cardiomyocytes [74]. Electrical stimulation also affects the cardiomyocyte microenvironment [75], and would regulate the cariogenic differentiation of stem cells. Previous studies have found that electrical stimulation promotes the mRNA expression of GATA4 and Nkx2.5 in BMSCs [76], indicating that electrical stimulation could induce cardiomyocyte differentiation of BMSCs. The current study shows TGF- $\beta 1$ may be involved in this process [77]. The expression of TGF- $\beta 1$ is increased during electrical stimulation. To investigate whether electrical stimulation induces the cardiomyocyte differentiation of BMSCs through TGF- $\beta 1$, BMSCs are treated with PFD (a TGF- $\beta 1$ inhibitor); protein levels of the cardiac markers CX43 and $\alpha$-actinin 2 are higher in the electrical stimulation group than in the electrical stimulation + PFD group, indicating that electrical stimulation induces the cardiomyocyte differentiation of BMSCs through TGF- $\beta 1$.

TGF- $\beta 1$ has known to be an important factor in embryonic heart development [78] and could induce cardiomyocyte differentiation of ES cells [79]. TGF- $\beta 1$ also could promote the cardiomyocyte differentiation of skeletal muscle-derived adult primitive cells and the cardiomyocyte-like differentiation of BMSCs [74]. This result shows that TGF- $\beta 1$ could induce BMSC cardiomyocyte differentiation. As the expansion of MSCs performed in cell culture medium with FBS has several problems including viral, bacterial, and prion [80], autologous serum has been considered. Autologous serum could regulate the proliferation and differentiation of MSCs [81] and enhance the cell viability. Chachques et al. [82] had transplanted autologous myoblasts which 
were cultured in autologous serum medium into LV infarcted patients to repair the jeopardized myocardium.

The electrical microenvironment is a key regulating factor of cardiomyocytes in vivo, and could trigger the cardiac-specific marker expression of various types of cells including fibroblasts [83], human mesenchymal stem cells [84], and ES cells [85]. Because of cardiac development of TGF- $\beta 1$ during embryogenesis [86] and various cardiac pathologies [87], a hypothesis that whether electrical stimulation could increase the cardiomyocytes differentiation of BMSCs with TGF- $\beta 1$ supplement is provided. The experiment demonstrates that electrostimulation would induce the cardiomyocyte differentiation of BMSCs via TGF- $\beta 1$ with a higher efficiency. However, the exact molecular mechanism and the signaling pathway mediating this process remain unknown, making it clear this could be useful in promoting the therapeutic efficacy of BMSCs for clinical use.

\section{Bone morphogenetic protein-2}

Bone morphogenetic proteins (BMPs) belonging to the TGF- $\beta$ family play roles in bone formation and cardiac diseases [88-90]. BMP-2 is a member of BMPs that has demonstrated therapeutic potential in MI by improving the contractility of cardiomyocytes and preventing cell death [91]. Whether it could regulate the cardiac differentiation of BMSCs requires further experiments. After treatment of BMSCs with BMP-2, Lv et al. [92] find that the differentiation of BMSCs into cardiomyocytes is enhanced by detecting the ultrastructural characterization, cardiomyocytespecific protein expression, and mRNA expression of transcription factors. Furthermore, BMP-2 combined with Salvianolic acid B extracted from Salvia miltiorrhiza could produce better efficiency. To data, BMP-2 plays a role in inducing the cardiomyocyte differentiation of BMSCs and can play a synergy role with Salvianolic acid B [92].

BMP-4 could induce cardiomyogenic differentiation of human amniotic epithelial cells [93] and promote cardiac differentiation of mouse ES cells with autologous serum supplement [94]. BMP-10 comes to be critical in embryogenesis of the heart. As a member of the BMP family, BMP-2 is known to induce various types of stem cells into osteoblasts, chondrocytes, or adipocytes [95]. The BMP signaling pathway also plays key roles in regulating proliferation, differentiation, and survival of cardiac progenitor cells [96]. The expression of BMP-2 is increased after myocardial infarction, not only anti-apoptosis, but also regulating the cardiomyocyte differentiation of cardiac progenitors [97]. By controlling the expression of BMP-2, ES cells could differentiate into cardiomyocytes [98]. A previous study also shows that BMP-2 might differentiate BMSCs into a myocardial cell line. Salvianolic acid B could play a cardioprotective role in ES cell-derived cardiomyocytes in a hypoxia condition. Salvianolic acid B also could regulate the differentiation of various types of cells. For example, Salvianolic acid B promotes osteogenesis of human mesenchymal stem cells [99] and enhances BMSC differentiation into type I alveolar epithelial cells [100]. Salvianolie acid B could be used to induce myocardial differentiation of BMSCs due to its function of cardioprotective and regulationg differentiation.

\section{Microenvironment}

Many research studies show that the cell-culture microenvironment may influence cell proliferation and differentiation. Recently, in-vitro studies have shown that culturing cells with specific medium could alter the cardiac-specific gene expression and differentiation of stem cells.

Wu et al. [101] utilize a high-voltage electrostatic field system to form nanosized collagen particles from collagen I solution. To further investigate whether collagen I nanomolecules could affect BMSC differentiation, BMSCs are cultured in medium with or without collagen I nanoparticles. After $24 \mathrm{~h}, 5$-aza is added to induce the cardiomyocyte differentiation of BMSCs. The expression of two transcription factors (GATA4 and Nkx2.5) and four cardiac-specific markers (cTnI, $\beta$-MHC, CX43, and cardiac $\alpha$-actin) are evaluated in BMSCs pretreatment with collagen I nanomolecules compared with BMSCs which not exposed to collagen I nanomolecules. These results demonstrate that collagen I nanomolecules can synergize with 5-aza to induce the cardiomyocyte differentiation of BMSCs, but the mechanism remains to be further explored.

Recently, in-vitro studies have shown that culturing substrates could modulate MSC differentiation [102]. Due to its physical and chemical properties and its effect on differentiation of MSCs [103], graphene has attracted much attention as a new type of MSC culture dish. To determine whether graphene could regulate the cardiomyocyte differentiation of human bone marrow-derived MSCs, Park et al. [104] conduct a series of studies. After cell seeding, cardiac-specific markers, including GATA4, cardiac actin, $\beta-\mathrm{MHC}$, and cTnT, are all higher in MSCs cultured on graphene than in MSCs cultured on coverslips. Furthermore, the level of cardiomyogenic differentiation-associated extracellular matrix proteins (collagen I, collagen III, collagen IV, fibronectin, and laminin) in MSCs cultured with graphene supplement is increased. Taken together, these data suggest that graphene could promote cardiomyocyte differentiation of MSCs through differentiation-associated ECM proteins and related signaling pathways.

Collagen scaffold has been used as a cell product in clinical trials for cardiac repair [105]. A recent study shows that MSCs could enhance the expression of cardiomyocyte-specific proteins in collagen patches and 
secrete cardiotrophic factors [106]. Extracellular matrix is an essential property of the microenvironment cells interact with, and has a key role in influencing cell behavior and determining cell fate. Furthermore, MSCs cultured in collagen patches provide not only structural support to damaged myocardium but also promote tissue repair and enhance regenerative potential of MSCs [107-109]. Previous studies have shown that stem cell-extracellular matrix (ECM) interactions may take part in the cardiomyogenic differentiation of stem cells [110-112], whereas cardiomyogenic differentiation-associated ECM proteins can induce cardiac differentiation of ES cells [113].

Graphene-based materials have emerged with various functions in multiple biomedical applications, such as gene and drug delivery, cancer therapy, and tissue regeneration [114-116], due to their electrical and chemical properties. Moreover, they have been used to culture and differentiate stem cells $[117,118]$. Ahadian et al. [119] find that graphene could induce spontaneous cardiac differentiation in embryoid bodies. Phosphorylated focal adhesion kinase (FAK) and ERK play an important role in regulating cardiomyogenic differentiation of stem cells [120]. Graphene could enhance stem cell adhesion, as the expression of FAK is increased [35], and it also increases the phosphorylation level of ERK. Park et al's [104] results are also consistent with this. Western blot analysis results show that these differentiation-related pathways, FAK and ERK, are both activated in graphenecultured MSCs.

\section{Others}

\section{Caveolin-1}

Caveolin-1 is an important part of caveolae, a specialized membrane invagination. Previous reports indicate that Caveolin-1 could play an important role in proliferation and differentiation of BMSCs [121-123], but the role of Caveolin-1 in cardiomyocyte differentiation of BMSCs remains unknown. Chen et al. [124] find that both mRNA and protein levels of Caveolin-1 are increased in 5-aza-treated BMSCs, suggesting that Caveolin-1 may be involved in the differentiation of BMSCs into cardiomyocytes. To further explore the role of Caveolin-1 in BMSC differentiation, Caveolin-1 siRNA is used. In the presence of siRNA, qRT-PCR and western blot analysis are performed to detect cardiac markers both at mRNA and protein levels, suggesting that knockdown of Caveolin-1 could enhance the cardiomyocyte differentiation of BMSCs [124].

The major finding of this study is that the downregulation of Caveolin-1 can promote the cardiomyocyte differentiation of BMSCs by regulating the activation of STAT3 signaling. Previous studies show that the expression of Caveolin-1 is increased in terminally differentiated mesenchymal lineage cells $[125,126]$, indicating that Caveolin-1 might prevent continued growth and differentiation. Guimaraes et al. [127] find that BMSCs isolated from the Caveolin-1 null mouse have an osteogenic differentiation potential, suggesting that Caveolin-1 could inhibit osteogenesis. Caveolin-1 also could block the neuronal differentiation and adipogenesis $[128,129]$. The cardiomyocyte differentiation of BMSCs is a complex and multisignal process. As stated, STAT3 could enhance the differentiation of transplanted BMSCs, and inhibition of its activation could suppress the differentiation of mouse ES cells into cardiomyocytes induced by the cooperation of leukemia inhibitory factor and BMP-2 [130]. But this may be contradictory. Natarajan et al.'s [131] research shows that inhibition of STAT3 could promote neuron differentiation at the expense of astrogliogenesis. In this study, the activation of STAT3 is drastically decreased during inhibition of the expression of Caveolin-1 in BMSCs with or without 5-aza induction. Although the study demonstrates that Caveolin-1 plays an important role in cardiomyocyte differentiation of BMSCs through the STAT3 signaling pathway, the change of STAT3 activation is not consistent with previous reports and requires further investigation.

\section{Vanilloid receptor 1}

Vanilloid receptor 1 (VR-1) is a $\mathrm{Ca}^{2+}$-permeable cationic channel belonging to the family of transient receptor potential ion channels [132]. The transient receptor potential ion channel family regulates neurons and osteocytes differentiation [133, 134]. VR-1 could promote osteoclast and osteoblast differentiation $[135,136]$. Previous studies have indicated that VR-1 is expressed in cardiomyocytes and has roles in cardiac remodeling and differentiation from mouse ES cells to cardiomyocytes [137, 138]. Whether VR1 could function in differentiation from BMSCs into cardiomyocytes is still not clear cut. After treatment with 5-aza, Ren et al. [139] find that the levels of VR-1 are evaluated in BMSCs, suggesting that VR-1 may play a role in the differentiation of BMSCs into cardiomyocytes. In order to further explore the potential role of VR-1 in cardiomyocyte differentiation of BMSCs, VR-1 is knocked down using siRNA. The mRNA and protein expressions of $\alpha-M H C, \alpha-$ actin, and $\mathrm{Nkx} 2.5$ in the 5-aza group are significantly lower than those in the negative control group. These data show that VR-1 knockdown would inhibit the cardiomyocyte differentiation of BMSCs induced by 5 -aza.

As previous evidence suggests that the $\mathrm{Wnt} / \beta$-catenin signaling pathway is involved in myocardial development $[140,141]$, the authors postulate that the $\mathrm{Wnt} / \beta$-catenin signaling pathway may be involved in the role of VR-1 in cardiomyocyte differentiation of BMSCs. However, subsequent experiments demonstrate that the expression of both $\beta$-catenin and ANIN2 positively correlated with the Wnt/ $\beta$-catenin signaling pathway is reduced when VR- 1 is 
knocked down in BMSCs. These results suggest that VR-1 could participate in the cardiomyocyte differentiation of BMSCs via the Wnt/ $\beta$-catenin signaling pathway [139].

\section{Histone deacetylase 1}

Currently, epigenetic modifications play an important role in cardiomyocyte differentiation processes of stem cells, especially histone acetylation [142, 143]. Previous studies have reported that HDAC1 knockdown could induce myocardial differentiation in P19CL6 cells and ES cells $[144,145]$. In a preliminary experiment, the decrease of HDAC1 expression in BMSCs is identified during cardiomyocytes differentiation [146]. But whether HDAC1 is involved in the process is unclear. To further investigate this hypothesis, $\mathrm{Lu}$ et al. construct the optimal HDAC1-RNAi lentiviral vector to reduce the expression of HDAC1 in BMSCs. After treatment of BMSCs with the HDAC1-RNAi lentiviral vector, mRNA levels of cardiac-specific genes such as Nkx2.5, GATA-4, MHC, CX43, and cTnT are detected by qRT-PCR. The results show that the lentivirus-infected BMSC expression of these five genes is significantly higher than the vector or $\mathrm{NC}$ vector, indicating that inhibition of HDAC1 expression could promote the directional differentiation of BMSCs into cardiomyocytes [146].

Epigenetic modification of histone acetylation has been demonstrated to play significant roles in differentiation process of stem cells. Histone deacetylase (HDAC) has many subtypes that participate in this process, such as CUDC-907 regulating adipocytic differentiation of bone marrow stromal cells via HDAC [147], IncRNA H19 inhibiting adipocyte differentiation of BMSCs through HDAC4-6 [148], and HDAC8 suppressing osteogenic differentiation of bone marrow stromal cells [149]. On treatment of BMSCs with nonspecific inhibitors of HDAC such as suberoylanilide hydroxamic acid and trichostatin A which could suppress multiple HDAC subtypes except $\mathrm{HDAC} 1$, the expression of cardiomyocyte-specific genes is increased $[142,150]$. In this study, cardiomyocytes differentiation is enhanced upon treatment of BMSCs with HDAC1-RNAi lentiviral vector, suggesting that HDAC1 also plays a role in cardiomyocytes differentiation of BMSCs.

\section{Prospects}

In recent years, a series of research studies have provided different approaches to induce the cardiomyocytes differentiation of BMSCs, including chemical inducers, cytokines, microRNAs, culture intermediaries, and so on. Recent studies have also shown that hMSCs cocultured with primary cardiomyocytes could promote nuclear modification of hMSCs for cardiomyogenic-like cell differentiation [151]. But there are also series of problems, such as the carcinogenicity of 5-aza and the low differentiation efficiency of many inducers, all of which hinder the clinical application of BMSC transplantation. However, these research studies supply a train of thought for inducing BMSCs to differentiate into cardiomyocytes as well. Transplantation of BMSCs will become a new promising




therapeutic strategy for clinical application in cardiac diseases in the future.

\section{Conclusions}

Many researches have been done to explore the efficient therapy of cardiac diseases, and stem cells transplanting has been a promising therapeutic strategy. Stem cells could be induced into cardiomyocytes, and then migrated to damaged location to play the therapeutic effect. BMSCs would be the ideal source of stem cells due to easy availability, powerful capacity of proliferation and immune modulatory properties. In this article, some regulatory factors which could induce the cardiomyoctes differentiation have been summarized, including 5-aza, miRNAs, cytokines, microenvironment, Caveolin-1, VR1 and HDAC1 (Fig. 1). More exploration are needed to elucidate the mechanism of BMSCs differentiate into cardiomyocytes and accelerate the clinical application.

\section{Abbreviations}

AMl: Acute myocardial infarction; ANP: Atrial natriuretic peptide;

5-aza: 5-Azacytidine; bFGF: Basic fibroblast growth factor; BMP: Bone morphogenetic protein; BMSC: Bone marrow-derived mesenchymal stem cell; CLC: Cardiomyocyte-like cell; cTnC: Cardiac troponin C; CTnl: Cardiac troponin l; CTnT: Cardiac troponin T; CX43: Connexin 43; DII-1: Delta-like 1; ES: Embryonic stem; FAK: Focal adhesion kinase; GATA4: GATA binding protein 4; HGF: Hepatocyte growth factor; IGF-1: Insulin-like growth factor-1; iPS: Induced pluripotent stem; Islet-1: Insulin gene enhancer binding protein ISL-1; a-MHC: Alpha myosin heavy chain; Nkx2.5: Homeobox protein 2.5; pIGF-1R: Phosphorylation IGF-1 receptor; STAT3: Targeting signal transducers and activators of transcription 3; VR-1: Vanilloid receptor 1

\section{Acknowledgements}

Not applicable.

\section{Funding}

This work was supported by the National Natural Science Fund of China (81170096/81573434).

\section{Availability of data and materials}

Data sharing is not applicable to this article as no datasets were generated or analyzed during the current study.

\section{Authors' contributions}

$\mathrm{ZmD}$ and $\mathrm{BzC}$ planned the review. XfG, YB, LZ, and BZ wrote the manuscript. $\mathrm{NZ}$ and $\mathrm{KC}$ proposed amendments and new directions of discussion. BzC was responsible for final approval of the manuscript. All authors read and approved the final manuscript.

\section{Ethics approval and consent to participate}

Not applicable.

\section{Consent for publication \\ Not applicable.}

\section{Competing interests}

The authors declare that they have no competing interests.

\section{Publisher's Note}

Springer Nature remains neutral with regard to jurisdictional claims in published maps and institutional affiliations.

\section{Author details}

'Department of Pharmacy, the Second Affiliated Hospital of Harbin Medical University, No. 246 Xuefu Road, Harbin, Heilongjiang Province 150081,
People's Republic of China. ${ }^{2}$ Department of Internal Diseases, Bashkir State Medical University, Ufa, Russia. ${ }^{3}$ Cell Therapy and Biotechnology in Regenerative Medicine Research Group, Pequeno Príncipe Faculty, Pelé Pequeno Príncipe Institute, Curitiba, Brazil.

Published online: 26 February 2018

\section{References}

1. Dowell JD, Rubart M, Pasumarthi KB, Soonpaa MH, Field L. Myocyte and myogenic stem cell transplantation in the heart. Cardiovasc Res. 2003;58:336-50

2. Murry CE, Field LJ, Menasche P. Cell-based cardiac repair: reflections at the 10-year point. Circulation. 2005;112:3174-83.

3. Wang H, Hao J, Hong CC. Cardiac induction of embryonic stem cells by a small molecule inhibitor of Wnt/beta-catenin signaling. ACS Chem Biol. 2011;6:192-7.

4. Mummery C, Ward-van Oostwaard D, Doevendans P, Spijker R, van den Brink S, Hassink R, van der Heyden M, Opthof T, Pera M, de la Riviere AB, Passier R, Tertoolen L. Differentiation of human embryonic stem cells to cardiomyocytes: role of coculture with visceral endoderm-like cells. Circulation. 2003;107:2733-40.

5. Kattman SJ, Witty AD, Gagliardi M, Dubois NC, Niapour M, Hotta A, Ellis J, Keller G. Stage-specific optimization of activin/nodal and BMP signaling promotes cardiac differentiation of mouse and human pluripotent stem cell lines. Cell Stem Cell. 2011;8:228-40.

6. Martin-Rendon E, Brunskill S, Doree C, Hyde C, Watt S, Mathur A, Stanworth S. Stem cell treatment for acute myocardial infarction. Cochrane Database Syst Rev. 2008;(4):CD006536.

7. Xu H, Yang YJ, Qian HY, Tang YD, Wang H, Zhang Q. Rosuvastatin treatment activates JAK-STAT pathway and increases efficacy of allogeneic mesenchymal stem cell transplantation in infarcted hearts. Circ J. 2011;75:1476-85.

8. Ryan JM, Barry FP, Murphy JM, Mahon BP. Mesenchymal stem cells avoid allogeneic rejection. J Inflamm (Lond). 2005;2(1):8.

9. Chang SA, Lee EJ, Kang HJ, Zhang SY, Kim JH, Li L, Youn SW, Lee CS, Kim KH, Won JY, Sohn JW, Park KW, Cho HJ, Yang SE, Oh WI, Yang YS, Ho WK, Park YB, Kim HS. Impact of myocardial infarct proteins and oscillating pressure on the differentiation of mesenchymal stem cells: effect of acute myocardial infarction on stem cell differentiation. Stem Cells. 2008;26:1901-12.

10. Quevedo HC, Hatzistergos KE, Oskouei BN, Feigenbaum GS, Rodriguez JE, Valdes D, Pattany PM, Zambrano JP, Hu Q, McNiece I, Heldman AW, Hare JM. Allogeneic mesenchymal stem cells restore cardiac function in chronic ischemic cardiomyopathy via trilineage differentiating capacity. Proc Natl Acad Sci U S A. 2009;106:14022-7.

11. Hahn JY, Cho HJ, Kang HJ, Kim TS, Kim MH, Chung JH, Bae JW, Oh BH, Park YB, Kim HS. Pre-treatment of mesenchymal stem cells with a combination of growth factors enhances gap junction formation, cytoprotective effect on cardiomyocytes, and therapeutic efficacy for myocardial infarction. J Am Coll Cardiol. 2008:51:933-43.

12. Collino F, Bruno S, Deregibus MC, Tetta C, Camussi G. MicroRNAs and mesenchymal stem cells. Vitam Horm. 2011;87:291-320.

13. Martin-Rendon E, Sweeney D, Lu F, Girdlestone J, Navarrete C, Watt SM. 5-Azacytidine-treated human mesenchymal stem/progenitor cells derived from umbilical cord, cord blood and bone marrow do not generate cardiomyocytes in vitro at high frequencies. Vox Sang. 2008;95:137-48.

14. Yoon BS, Yoo SJ, Lee JE, You S, Lee HT, Yoon HS. Enhanced differentiation of human embryonic stem cells into cardiomyocytes by combining hanging drop culture and 5-azacytidine treatment. Differentiation. 2006;74:149-59.

15. Makino S, Fukuda K, Miyoshi S, Konishi F, Kodama H, Pan J, Sano M, Takahashi T, Hori S, Abe H, Hata J, Umezawa A, Ogawa S. Cardiomyocytes can be generated from marrow stromal cells in vitro. J Clin Invest. 1999;103:697-705.

16. Xu W, Zhang X, Qian H, Zhu W, Sun X, Hu J, Zhou H, Chen Y. Mesenchymal stem cells from adult human bone marrow differentiate into a cardiomyocyte phenotype in vitro. Exp Biol Med (Maywood). 2004;229:623-31.

17. Antonitsis $P$, loannidou-Papagiannaki E, Kaidoglou A, Papakonstantinou C. In vitro cardiomyogenic differentiation of adult human bone marrow mesenchymal stem cells. The role of 5-azacytidine. Interact Cardiovasc Thorac Surg. 2007;6:593-7.

18. Alagesanand S, Griffin MD. Autologous and allogeneic mesenchymal stem cells in organ transplantation: what do we know about their safety and efficacy? Curr Opin Organ Transplant. 2014;19:65-72. 
19. Gu S, Jin L, Zhang F, Sarnow P, Kay MA. Biological basis for restriction of microRNA targets to the $3^{\prime}$ untranslated region in mammalian mRNAs. Nat Struct Mol Biol. 2009;16:144-50.

20. Wang K, Sun T, Li N, Wang Y, Wang JX, Zhou LY, Long B, Liu CY, Liu F, Li PF. MDRL IncRNA regulates the processing of miR-484 primary transcript by targeting miR-361. PLoS Genet. 2014;10:e1004467.

21. Kim YJ, Hwang SJ, Bae YC, Jung JS. MiR-21 regulates adipogenic differentiation through the modulation of TGF-beta signaling in mesenchymal stem cells derived from human adipose tissue. Stem Cells. 2009;27:3093-102.

22. Wu T, Zhou H, Hong $Y$, Li J, Jiang $X$, Huang $H$. miR-30 family members negatively regulate osteoblast differentiation. J Biol Chem. 2012;287:7503-11.

23. Zhao XL, Yang B, Ma LN, Dong YH. MicroRNA-1 effectively induces differentiation of myocardial cells from mouse bone marrow mesenchymal stem cells. Artif Cells Nanomed Biotechnol. 2016;44:1665-70.

24. Cai B, Li J, Wang J, Luo X, Ai J, Liu Y, Wang N, Liang H, Zhang M, Chen N, Wang G, Xing S, Zhou X, Yang B, Wang X, Lu Y. microRNA-124 regulates cardiomyocyte differentiation of bone marrow-derived mesenchymal stem cells via targeting STAT3 signaling. Stem Cells. 2012;30:1746-55.

25. Shen X, Pan B, Zhou H, Liu L, Lv T, Zhu J, Huang X, Tian J. Differentiation of mesenchymal stem cells into cardiomyocytes is regulated by miRNA-1-2 via WNT signaling pathway. J Biomed Sci. 2017;24:29.

26. Huang F, Tang L, Fang ZF, Hu XQ, Pan JY, Zhou SH. Corrigendum to "miR-1-Mediated Induction of Cardiogenesis in Mesenchymal Stem Cells via Downregulation of Hes-1". Biomed Res Int. 2016;2016:8510747.

27. Deng $L, H u ~ G$, Jin L, Wang $C$, and Niu H. Involvement of microRNA-23b in TNF-alpha-reduced BMSC osteogenic differentiation via targeting runx2. J Bone Miner Metab. 2017

28. Li H, Yu B, Zhang Y, Pan Z, Xu W. Jagged1 protein enhances the differentiation of mesenchymal stem cells into cardiomyocytes. Biochem Biophys Res Commun. 2006;341:320-5.

29. Ivey KN, Muth A, Arnold J, King FW, Yeh RF, Fish JE, Hsiao EC, Schwartz RJ, Conklin BR, Bernstein HS, Srivastava D. MicroRNA regulation of cell lineages in mouse and human embryonic stem cells. Cell Stem Cell. 2008;2:219-29.

30. Kim YS, Kim MJ, Koo TH, Kim JD, Koun S, Ham HJ, Lee YM, Rhee M, Yeo SY, Huh TL. Histone deacetylase is required for the activation of Wnt/beta-catenin signaling crucial for heart valve formation in zebrafish embryos. Biochem Biophys Res Commun. 2012;423:140-6.

31. Gwak J, Hwang SG, Park HS, Choi SR, Park SH, Kim H, Ha NC, Bae SJ, Han JK, Kim DE, Cho JW, Oh S. Small molecule-based disruption of the Axin/beta-catenin protein complex regulates mesenchymal stem cell differentiation. Cell Res. 2012;22:237-47.

32. Huang $X$, Li D, Wang Z, Huang Z, Dong X, Li C, Lan J. Study of microRNAs targeted Dvl2 on the osteoblasts differentiation of rat BMSCs in hyperlipidemia environment. J Cell Physiol. 2017. https://doi.org/10.1002/jcp.26392.

33. Kapsimali M, Kloosterman WP, de Bruijn E, Rosa F, Plasterk RH, Wilson SW. MicroRNAs show a wide diversity of expression profiles in the developing and mature central nervous system. Genome Biol. 2007:8:R173.

34. Arminan A, Gandia C, Bartual M, Garcia-Verdugo JM, Lledo E, Mirabet V, Llop M, Barea J, Montero JA, Sepulveda P. Cardiac differentiation is driven by NKX2.5 and GATA4 nuclear translocation in tissue-specific mesenchymal stem cells. Stem Cells Dev. 2009;18:907-18.

35. Wu J, Zhao J, Sun L, Pan Y, Wang H, Zhang WB. Long non-coding RNA H19 mediates mechanical tension-induced osteogenesis of bone marrow mesenchymal stem cells via FAK by sponging miR-138. Bone. 2017;108:62-70.

36. Haylor J, Hickling H, El Eter E, Moir A, Oldroyd S, Hardisty C, El Nahas AM. JB3, an IGF-I receptor antagonist, inhibits early renal growth in diabetic and uninephrectomized rats. J Am Soc Nephrol. 2000;11:2027-35.

37. Hu C, Wu Y, Wan Y, Wang Q, Song J. Introduction of hIGF-1 gene into bone marrow stromal cells and its effects on the cell's biological behaviors. Cell Transplant. 2008;17:1067-81.

38. Schnabel LV, Lynch ME, van der Meulen MC, Yeager AE, Kornatowski MA, Nixon AJ. Mesenchymal stem cells and insulin-like growth factor-I gene-enhanced mesenchymal stem cells improve structural aspects of healing in equine flexor digitorum superficialis tendons. J Orthop Res. 2009;27:1392-8.

39. Liechty KW, MacKenzie TC, Shaaban AF, Radu A, Moseley AM, Deans R, Marshak DR, Flake AW. Human mesenchymal stem cells engraft and demonstrate site-specific differentiation after in utero transplantation in sheep. Nat Med. 2000;6:1282-6.
40. Orlic D, Kajstura J, Chimenti S, Limana F, Jakoniuk I, Quaini F, Nadal-Ginard B, Bodine DM, Leri A, Anversa P. Mobilized bone marrow cells repair the infarcted heart, improving function and survival. Proc Natl Acad Sci U S A. 2001:98:10344-9.

41. Kudo M, Wang Y, Wani MA, Xu M, Ayub A, Ashraf M. Implantation of bone marrow stem cells reduces the infarction and fibrosis in ischemic mouse heart. J Mol Cell Cardiol. 2003;35:1113-9.

42. Miyahara Y, Nagaya N, Kataoka M, Yanagawa B, Tanaka K, Hao H, Ishino K, Ishida H, Shimizu T, Kangawa K, Sano S, Okano T, Kitamura S, Mori H. Monolayered mesenchymal stem cells repair scarred myocardium after myocardial infarction. Nat Med. 2006;12:459-65.

43. Ellison GM, Torella D, Dellegrottaglie S, Perez-Martinez C, Perez de Prado A, Vicinanza C, Purushothaman S, Galuppo V, laconetti C, Waring CD, Smith A, Torella M, Cuellas Ramon C, Gonzalo-Orden JM, Agosti V, Indolfi C, Galinanes M, Fernandez-Vazquez F, Nadal-Ginard B. Endogenous cardiac stem cell activation by insulin-like growth factor-1/hepatocyte growth factor intracoronary injection fosters survival and regeneration of the infarcted pig heart. J Am Coll Cardiol. 2011;58:977-86.

44. Savi M, Bocchi L, Fiumana E, Karam JP, Frati C, Bonafe F, Cavalli S, Morselli PG, Guarnieri C, Caldarera CM, Muscari C, Montero-Menei CN, Stilli D, Quaini F, Musso E. Enhanced engraftment and repairing ability of human adipose-derived stem cells, conveyed by pharmacologically active microcarriers continuously releasing HGF and IGF-1, in healing myocardial infarction in rats. J Biomed Mater Res A. 2015;103:3012-25.

45. Zhang GW, Gu TX, Guan XY, Sun XJ, Qi X, Li XY, Wang XB, Lv F, Yu L, Jiang DQ, Tang R. HGF and IGF-1 promote protective effects of allogeneic BMSC transplantation in rabbit model of acute myocardial infarction. Cell Prolif. 2015:48:661-70.

46. Kofidis T, de Bruin JL, Yamane T, Balsam LB, Lebl DR, Swijnenburg RJ, Tanaka M, Weissman IL, Robbins RC. Insulin-like growth factor promotes engraftment, differentiation, and functional improvement after transfer of embryonic stem cells for myocardial restoration. Stem Cells. 2004;22:1239-45.

47. Shuang T, Fu M, Yang G, Wu L, Wang R. The interaction of IGF-1/IGF-1R and hydrogen sulfide on the proliferation of mouse primary vascular smooth muscle cells. Biochem Pharmacol. 2017.

48. Gong H, Wang X, Wang L, Liu Y, Wang J, Lv Q, Pang H, Zhang Q, Wang Z. Inhibition of IGF-1 receptor kinase blocks the differentiation into cardiomyocyte-like cells of BMSCs induced by IGF-1. Mol Med Rep. 2017;16:787-93.

49. McMahon LA, Prendergast PJ, Campbell VA. A comparison of the involvement of p38, ERK1/2 and PI3K in growth factor-induced chondrogenic differentiation of mesenchymal stem cells. Biochem Biophys Res Commun. 2008;368:990-5.

50. Laugwitz KL, Moretti A, Caron L, Nakano A, Chien KR. Islet1 cardiovascular progenitors: a single source for heart lineages? Development. 2008;135:193-205.

51. Nakano A, Nakano H, Chien KR. Multipotent islet-1 cardiovascular progenitors in development and disease. Cold Spring Harb Symp Quant Biol. 2008;73:297-306.

52. Cai CL, Liang X, Shi Y, Chu PH, Pfaff SL, Chen J, Evans S. Isl1 identifies a cardiac progenitor population that proliferates prior to differentiation and contributes a majority of cells to the heart. Dev Cell. 2003;5:877-89.

53. Yi Q, Xu H, Yang K, Wang Y, Tan B, Tian J, Zhu J. Islet-1 induces the differentiation of mesenchymal stem cells into cardiomyocyte-like cells through the regulation of Gen5 and DNMT-1. Mol Med Rep. 2017;15:2511-20

54. Bhuvanalakshmi G, Arfuso F, Kumar AP, Dharmarajan A, Warrier S. Epigenetic reprogramming converts human Wharton's jelly mesenchymal stem cells into functional cardiomyocytes by differential regulation of Wnt mediators. Stem Cell Res Ther. 2017:8:185.

55. Zhang XL, Wu J, Wang J, Shen T, Li H, Lu J, Gu Y, Kang Y, Wong CH, Ngan CY, Shao Z, Zhao $X$. Integrative epigenomic analysis reveals unique epigenetic signatures involved in unipotency of mouse female germline stem cells. Genome Biol. 2016;17:162.

56. Hawkins RD, Hon GC, Lee LK, Ngo Q, Lister R, Pelizzola M, Edsall LE, Kuan S, Luu Y, Klugman S, Antosiewicz-Bourget J, Ye Z, Espinoza C, Agarwahl S, Shen L, Ruotti V, Wang W, Stewart R, Thomson JA, Ecker JR, Ren B. Distinct epigenomic landscapes of pluripotent and lineage-committed human cells. Cell Stem Cell. 2010;6:479-91.

57. Hu Z, Song N, Zheng M, Liu X, Liu Z, Xing J, Ma J, Guo W, Yao Y, Peng H, Xin M, Zhou DX, Ni Z, Sun Q. Histone acetyltransferase GCN5 is essential for heat stress-responsive gene activation and thermotolerance in Arabidopsis. Plant J. 2015;84:1178-91. 
58. Rosenblatt-Velin N, Lepore MG, Cartoni C, Beermann F, Pedrazzini T. FGF-2 controls the differentiation of resident cardiac precursors into functional cardiomyocytes. J Clin Invest. 2005;115:1724-33.

59. Khezri S, Valojerdi MR, Sepehri H, Baharvand H. Effect of basic fibroblast growth factor on cardiomyocyte differentiation from mouse embryonic stem cells. Saudi Med J. 2007;28:181-6.

60. Hafez P, Jose S, Chowdhury SR, Ng MH, Ruszymah BH. Abdul Rahman Mohd R. Cardiomyogenic differentiation of human sternal bone marrow mesenchymal stem cells using a combination of basic fibroblast growth factor and hydrocortisone. Cell Biol Int. 2016;40:55-64.

61. Yang X, Hao J, Mao Y, Jin ZQ, Cao R, Zhu CH, Liu XH, Liu C, Ding XL, Wang $X D$, Chen D, Wu XZ. bFGF promotes migration and induces cancerassociated fibroblast differentiation of mouse bone mesenchymal stem cells to promote tumor growth. Stem Cells Dev. 2016;25(21):1629-39.

62. Rodrigues $M$, Griffith $L G$, Wells $A$. Growth factor regulation of proliferation and survival of multipotential stromal cells. Stem Cell Res Ther. 2010;1:32.

63. Khanabdali R, Rosdah AA, Dusting GJ, Lim SY. Harnessing the secretome of cardiac stem cells as therapy for ischemic heart disease. Biochem Pharmacol. 2016;113:1-11.

64. Wang X, Zhen L, Miao H, Sun Q, Yang Y, Que B, Lopes Lao EP, Wu X, Ren H, Shi S, Lau WB, Ma X, Ma C, Nie S. Concomitant retrograde coronary venous infusion of basic fibroblast growth factor enhances engraftment and differentiation of bone marrow mesenchymal stem cells for cardiac repair after myocardial infarction. Theranostics. 2015;5:995-1006.

65. Bagchi AK, Sharma A, Dhingra S, Lehenbauer Ludke AR, Al-Shudiefat AA, Singal PK. Interleukin-10 activates Toll-like receptor 4 and requires MyD88 for cardiomyocyte survival. Cytokine. 2013;61:304-14.

66. Van Tassell BW, Toldo S, Mezzaroma E, Abbate A. Targeting interleukin-1 in heart disease. Circulation. 2013;128:1910-23.

67. Mohr T, Haudek-Prinz V, Slany A, Grillari J, Micksche M, Gerner C. Proteome profiling in IL-1beta and VEGF-activated human umbilical vein endothelial cells delineates the interlink between inflammation and angiogenesis. PLoS One. 2017;12:e0179065.

68. Khajeniazi S, Solati M, Yazdani Y, Soleimani M, Kianmehr A. Synergistic induction of cardiomyocyte differentiation from human bone marrow mesenchymal stem cells by interleukin 1 beta and 5-azacytidine. Biol Chem. 2016;397:1355-64.

69. Nagata Y, Kiyono T, Okamura K, Goto YI, Matsuo M, Kemoto-Uezumi M, Hashimoto N. Interleukin-1 beta (IL-1 beta)-induced Notch ligand Jagged1 suppresses mitogenic action of IL-1 beta on human dystrophic myogenic cells. PLoS One. 2017;12:e0188821.

70. Sonomoto K, Yamaoka K, Oshita K, Fukuyo S, Zhang X, Nakano K, Okada Y, Tanaka Y. Interleukin-1 beta induces differentiation of human mesenchymal stem cells into osteoblasts via the Wnt-5a/receptor tyrosine kinase-like orphan receptor 2 pathway. Arthritis Rheum. 2012;64:3355-63.

71. Massague J, Blain SW, Lo RS. TGFbeta signaling in growth control, cancer, and heritable disorders. Cell. 2000;103:295-309.

72. Siegeland PM, Massague J. Cytostatic and apoptotic actions of TGF-beta in homeostasis and cancer. Nat Rev Cancer. 2003;3:807-21.

73. Gwak SJ, Bhang SH, Yang HS, Kim SS, Lee DH, Lee SH, Kim BS. In vitro cardiomyogenic differentiation of adipose-derived stromal cells using transforming growth factor-beta1. Cell Biochem Funct. 2009;27:148-54.

74. Rouhi L, Kajbafzadeh AM, Modaresi M, Shariati M, Hamrahi D. Autologous serum enhances cardiomyocyte differentiation of rat bone marrow mesenchymal stem cells in the presence of transforming growth factor-beta1 (TGF-beta1). In Vitro Cell Dev Biol Anim. 2013;49:287-94.

75. Ingber DE. Mechanical signaling and the cellular response to extracellular matrix in angiogenesis and cardiovascular physiology. Circ Res. 2002;91:877-87.

76. Yan Z, Yang G, Cui L, He X, Kuang W, Wu W, Liu X, Li L. Effects of electrical stimulation on the differentiation of mesenchymal stem cells into cardiomyocyte-like cells. Sheng Wu Yi Xue Gong Cheng Xue Za Zhi. 2013:30:556-61.

77. He X, Li L, Tang M, Zeng Y, Li H, Yu X. Biomimetic electrical stimulation induces rat bone marrow mesenchymal stem cells to differentiate into cardiomyocyte-like cells via TGF-beta 1 in vitro. Prog Biophys Mol Biol. 2017.

78. Ramesh S, Singh A, Cibi DM, Hausenloy DJ, Singh MK. In vitro culture of epicardial cells from mouse embryonic heart. J Vis Exp. 2016;(110).

79. Shikatani EA, Chandy M, Besla R, Li CC, Momen A, El-Mounayri O, Robbins CS, Husain M. c-Myb regulates proliferation and differentiation of adventitial $\mathrm{Sca} 1+$ vascular smooth muscle cell progenitors by transactivation of myocardin. Arterioscler Thromb Vasc Biol. 2016;36:1367-76.
80. Nimura A, Muneta T, Koga H, Mochizuki T, Suzuki K, Makino H, Umezawa A, Sekiya I. Increased proliferation of human synovial mesenchymal stem cells with autologous human serum: comparisons with bone marrow mesenchymal stem cells and with fetal bovine serum. Arthritis Rheum. 2008:58:501-10.

81. Mizuno M, Katano H, Otabe K, Komori K, Kohno Y, Fujii S, Ozeki N, Horie M, Tsuji K, Koga H, Muneta T, Sekiya I. Complete human serum maintains viability and chondrogenic potential of human synovial stem cells: suitable conditions for transplantation. Stem Cell Res Ther. 2017;8:144.

82. Chachques JC, Herreros J, Trainini J, Juffe A, Rendal E, Prosper F, Genovese J. Autologous human serum for cell culture avoids the implantation of cardioverter-defibrillators in cellular cardiomyoplasty. Int I Cardiol. 2004;95 Suppl 1:S29-33.

83. Guerrero-Robles Cl, Vazquez-Zapien GJ, Mata-Miranda MM, Noriega-Gonzalez JE, Gonzalez-Diaz CA. Electrical bioimpedance spectroscopy as biosensor technique to identify cells lineages and cell differentiation process. Conf Proc IEEE Eng Med Biol Soc. 2017:2017:3568-71.

84. Thrivikraman G, Madras G, Basu B. Electrically driven intracellular and extracellular nanomanipulators evoke neurogenic/cardiomyogenic differentiation in human mesenchymal stem cells. Biomaterials. 2016;77:26-43.

85. Koga T, Shiraki N, Yano S, Suico MA, Morino-Koga S, Sato T, Shuto T, Kume S, Kai H. Mild electrical stimulation with heat shock guides differentiation of embryonic stem cells into Pdx1-expressing cells within the definitive endoderm. BMC Biotechnol. 2017;17:14.

86. Valdimarsdottirand $G$, Mummery C. Functions of the TGFbeta superfamily in human embryonic stem cells. APMIS. 2005;113:773-89.

87. Al-Tamari HM, Dabral S, Schmall A, Sarvari P, Ruppert C, Paik J, DePinho RA, Grimminger F, Eickelberg O, Guenther A, Seeger W, Savai R, Pullamsetti SS. FoxO3 an important player in fibrogenesis and therapeutic target for idiopathic pulmonary fibrosis. EMBO Mol Med. 2017.

88. Salazar VS, Gamer LW, Rosen V. BMP signalling in skeletal development, disease and repair. Nat Rev Endocrinol. 2016;12:203-21.

89. Lu J, Sun B, Huo R, Wang YC, Yang D, Xing Y, Xiao XL, Xie X, Dong DL. Bone morphogenetic protein-2 antagonizes bone morphogenetic protein-4 induced cardiomyocyte hypertrophy and apoptosis. J Cell Physiol. 2014;229:1503-10

90. Sun B, Huo R, Sheng Y, Li Y, Xie X, Chen C, Liu HB, Li N, Li CB, Guo WT, Zhu JX, Yang BF, Dong DL. Bone morphogenetic protein-4 mediates cardiac hypertrophy, apoptosis, and fibrosis in experimentally pathological cardiac hypertrophy. Hypertension. 2013;61:352-60.

91. Ebelt H, Hillebrand I, Arlt S, Zhang Y, Kostin S, Neuhaus H, Muller-Werdan U, Schwarz E, Werdan K, Braun T. Treatment with bone morphogenetic protein 2 limits infarct size after myocardial infarction in mice. Shock. 2013;39:353-60.

92. LV Y, Gao CW, Liu B, Wang HY, Wang HP. BMP-2 combined with salvianolic acid $B$ promotes cardiomyocyte differentiation of rat bone marrow mesenchymal stem cells. Kaohsiung J Med Sci. 2017;33:477-85.

93. Han X, Wan Q, Wu W, Zheng A, Li L, Liu X. Activin A and BMP-4 induce cardiomyocyte-like cells differentiation of human amniotic epithelial cells. Sheng Wu Yi Xue Gong Cheng Xue Za Zhi. 2011;28:1217-22.

94. Tahaand MF, Valojerdi MR. Effect of bone morphogenetic protein-4 on cardiac differentiation from mouse embryonic stem cells in serum-free and low-serum media. Int J Cardiol. 2008;127:78-87.

95. Zhou N, Li Q, Lin X, Hu N, Liao JY, Lin LB, Zhao C, Hu ZM, Liang X, Xu W, Chen H, Huang W. BMP2 induces chondrogenic differentiation, osteogenic differentiation and endochondral ossification in stem cells. Cell Tissue Res. 2016;366:101-11.

96. Liu C, Chen L, Zeng J, Cui J, Ning JN, Wang GS, Belguise K, Wang X, Qian GS, Lu KZ, Yi B. Bone morphogenic protein-2 regulates the myogenic differentiation of PMVECs in CBDL rat serum-induced pulmonary microvascular remodeling. Exp Cell Res. 2015;336:109-18.

97. Zhang Z, Li H, Ma Z, Feng J, Gao P, Dong H. Efficient cardiomyogenic differentiation of bone marrow mesenchymal stromal cells by combination of Wnt1 1 and bone morphogenetic protein 2. Exp Biol Med (Maywood). 2012:237:768-76.

98. Hoxha E, Lambers E, Wasserstrom JA, Mackie A, Ramirez V, Abramova T, Verma SK, Krishnamurthy P, Kishore R. Elucidation of a novel pathway through which $\mathrm{HDACl}$ controls cardiomyocyte differentiation through expression of SOX-17 and BMP2. PLoS One. 2012;7:e45046.

99. Xu D, Xu L, Zhou C, Lee WY, Wu T, Cui L, Li G. Salvianolic acid B promotes osteogenesis of human mesenchymal stem cells through activating ERK signaling pathway. Int J Biochem Cell Biol. 2014;51:1-9. 
100. Gao P, Yang J, Gao X, Xu D, Niu D, Li J, Wen Q. Salvianolic acid B improves bone marrow-derived mesenchymal stem cell differentiation into alveolar epithelial cells type I via Wnt signaling. Mol Med Rep. 2015;12:1971-6.

101. Wu YJ, Chen SY, Chang SJ, Kuo SM. Enhanced differentiation of rat MSCs into cardiomyocytes with 5-azacytidine/collagen I nano-molecules. Conf Proc IEEE Eng Med Biol Soc. 2013;2013:322-5.

102. Kim HN, Jiao A, Hwang NS, Kim MS, Kang DH, Kim DH, Suh KY. Nanotopography-guided tissue engineering and regenerative medicine. Adv Drug Deliv Rev. 2013;65:536-58.

103. Lee WC, Lim CH, Shi H, Tang LA, Wang Y, Lim CT, Loh KP. Origin of enhanced stem cell growth and differentiation on graphene and graphene oxide. ACS Nano. 2011;5:7334-41.

104. Park J, Park S, Ryu S, Bhang SH, Kim J, Yoon JK, Park YH, Cho SP, Lee S, Hong BH, Kim BS. Graphene-regulated cardiomyogenic differentiation process of mesenchymal stem cells by enhancing the expression of extracellular matrix proteins and cell signaling molecules. Adv Healthc Mater. 2014;3:176-81.

105. Nart J, de Tapia B, Pujol A, Pascual A, Valles C. Vancomycin and tobramycin impregnated mineralized allograft for the surgical regenerative treatment of peri-implantitis: a 1-year follow-up case series. Clin Oral Investig. 2017. https://doi.org/10.1007/s00784-017-2310-0.

106. Rashedi I, Talele N, Wang XH, Hinz B, Radisic M, Keating A. Collagen scaffold enhances the regenerative properties of mesenchymal stromal cells. PLoS One. 2017;12:e0187348.

107. Dayan V, Yannarelli G, Billia F, Filomeno P, Wang XH, Davies JE, Keating A. Mesenchymal stromal cells mediate a switch to alternatively activated monocytes/macrophages after acute myocardial infarction. Basic Res Cardiol. 2011;106:1299-310.

108. Nemeth K, Leelahavanichkul A, Yuen PS, Mayer B, Parmelee A, Doi K, Robey PG, Leelahavanichkul K, Koller BH, Brown JM, Hu X, Jelinek I, Star RA, Mezey E. Bone marrow stromal cells attenuate sepsis via prostaglandin E(2)-dependent reprogramming of host macrophages to increase their interleukin-10 production. Nat Med. 2009;15:42-9.

109. Waterman RS, Tomchuck SL, Henkle SL, Betancourt AM. A new mesenchymal stem cell (MSC) paradigm: polarization into a pro-inflammatory MSC1 or an immunosuppressive MSC2 phenotype. PLoS One. 2010;5:e10088.

110. Engler AJ, Sen S, Sweeney HL, Discher DE. Matrix elasticity directs stem cell lineage specification. Cell. 2006;126:677-89.

111. Martino MM, Mochizuki M, Rothenfluh DA, Rempel SA, Hubbell JA, Barker TH. Controlling integrin specificity and stem cell differentiation in 2D and 3D environments through regulation of fibronectin domain stability. Biomaterials. 2009;30:1089-97.

112. Ogura N, Kawada M, Chang WJ, Zhang Q, Lee SY, Kondoh T, Abiko Y. Differentiation of the human mesenchymal stem cells derived from bone marrow and enhancement of cell attachment by fibronectin. J Oral Sci. 2004:46:207-13.

113. Sato $H$, Takahashi M, Ise $H$, Yamada A, Hirose $S$, Tagawa $Y$, Morimoto $H$, Izawa A, lkeda U. Collagen synthesis is required for ascorbic acid-enhanced differentiation of mouse embryonic stem cells into cardiomyocytes. Biochem Biophys Res Commun. 2006;342:107-12.

114. Bayer IS. Thermomechanical properties of polylactic acid-graphene composites: a state-of-the-art review for biomedical applications. Materials (Basel). 2017;10(7)

115. Wang Y, Wang H, Liu D, Song S, Wang X, Zhang H. Graphene oxide covalently grafted upconversion nanoparticles for combined NIR mediated imaging and photothermal/photodynamic cancer therapy. Biomaterials. 2013;34:7715-24.

116. Wang L, Wu Y, Hu T, Guo B, Ma PX. Electrospun conductive nanofibrous scaffolds for engineering cardiac tissue and 3D bioactuators. Acta Biomater. 2017;59:68-81.

117. Shah S, Yin PT, Uehara TM, Chueng ST, Yang L, Lee KB. Guiding stem cell differentiation into oligodendrocytes using graphene-nanofiber hybrid scaffolds. Adv Mater. 2014;26:3673-80.

118. Kim TH, Shah S, Yang L, Yin PT, Hossain MK, Conley B, Choi JW, Lee KB. Controlling differentiation of adipose-derived stem cells using combinatorial graphene hybrid-pattern arrays. ACS Nano. 2015;9:3780-90.

119. Ahadian S, Zhou Y, Yamada S, Estili M, Liang X, Nakajima K, Shiku H, Matsue T. Graphene induces spontaneous cardiac differentiation in embryoid bodies. Nanoscale. 2016;8:7075-84.

120. Choi SH, Jung SY, Yoo SM, Asahara T, Suh W, Kwon SM, Baek SH. Amine-enriched surface modification facilitates expansion, attachment, and maintenance of human cardiac-derived c-kit positive progenitor cells. Int J Cardiol. 2013;168:100-7.
121. Baker N, Zhang G, You Y, Tuan RS. Caveolin-1 regulates proliferation and osteogenic differentiation of human mesenchymal stem cells. J Cell Biochem. 2012;113:3773-87.

122. Lee MY, Ryu JM, Lee SH, Park JH, Han HJ. Lipid rafts play an important role for maintenance of embryonic stem cell self-renewal. J Lipid Res. 2010:51:2082-9.

123. Wang S, Kan Q, Sun Y, Han R, Zhang G, Peng T, Jia Y. Caveolin-1 regulates neural differentiation of rat bone mesenchymal stem cells into neurons by modulating Notch signaling. Int J Dev Neurosci. 2013;31:30-5.

124. Chen Y, Wang C, Huang Q, Wu D, Cao J, Xu X, Yang C, Li X. Caveolin-1 plays an important role in the differentiation of bone marrow-derived mesenchymal stem cells into cardiomyocytes. Cardiology. 2017;136:40-8.

125. Bandara N, Gurusinghe S, Lim SY, Chen H, Chen S, Wang D, Hilbert B, Wang LX, Strappe P. Molecular control of nitric oxide synthesis through eNOS and caveolin-1 interaction regulates osteogenic differentiation of adipose-derived stem cells by modulation of Wnt/beta-catenin signaling. Stem Cell Res Ther. 2016;7:182.

126. Guan X, Wang N, Cui F, Liu Y, Liu P, Zhao J, Han C, Li X, Leng Z, Li Y, Ji X, Zou W, Liu J. Caveolin-1 is essential in the differentiation of human adipose-derived stem cells into hepatocyte-like cells via an MAPK pathway-dependent mechanism. Mol Med Rep. 2016;13:1487-94.

127. Guimaraes SE, Rothschild MF, Ciobanu D, Stahl CH, Lonergan SM. SNP discovery, expression and association analysis for the SDHD gene in pigs. J Anim Breed Genet. 2007;124:139-43.

128. Volpicelli F, Caiazzo M, Moncharmont B, di Porzio U, Colucci-D'Amato L. Neuronal differentiation dictates estrogen-dependent survival and ERK1/2 kinetic by means of caveolin-1. PLoS One. 2014;9:e109671.

129. Chang CC, Chen CY, Wen HC, Huang CY, Hung MS, Lu HC, Chen WL, Chang $\mathrm{CH}$. Caveolin-1 secreted from adipose tissues and adipocytes functions as an adipogenesis enhancer. Obesity (Silver Spring). 2017;25:1932-40.

130. Xie X, Chan KS, Cao F, Huang M, Li Z, Lee A, Weissman IL, Wu JC. Imaging of STAT3 signaling pathway during mouse embryonic stem cell differentiation. Stem Cells Dev. 2009;18:205-14.

131. Natarajan R, Singal V, Benes R, Gao J, Chan H, Chen H, Yu Y, Zhou J, Wu P. STAT3 modulation to enhance motor neuron differentiation in human neural stem cells. PLoS One. 2014;9:e100405.

132. Xia R, Dekermendjian K, Lullau E, Dekker N. TRPV1: a therapy target that attracts the pharmaceutical interests. Adv Exp Med Biol. 2011;704:637-65.

133. Leuner K, Kraus M, Woelfle U, Beschmann H, Harteneck C, Boehncke WH, Schempp CM, Muller WE. Reduced TRPC channel expression in psoriatic keratinocytes is associated with impaired differentiation and enhanced proliferation. PLoS One. 2011;6:e14716.

134. Shin HY, Hong YH, Jang SS, Chae HG, Paek SL, Moon HE, Kim DG, Kim J, Paek SH, Kim SJ. A role of canonical transient receptor potential 5 channel in neuronal differentiation from A2B5 neural progenitor cells. PLoS One. 2010;5:e10359.

135. Bellini G, Torella M, Manzo I, Tortora C, Luongo L, Punzo F, Colacurci N, Nobili B, Maione S, Rossi F. PKCbetall-mediated cross-talk of TRPV1/CB2 modulates the glucocorticoid-induced osteoclast overactivity. Pharmacol Res. 2017;115:267-74.

136. Mikami R, Mizutani K, Aoki A, Tamura Y, Aoki K, Izumi Y. Low-level ultrahighfrequency and ultrashort-pulse blue laser irradiation enhances osteoblast extracellular calcification by upregulating proliferation and differentiation via transient receptor potential vanilloid 1. Lasers Surg Med. 2017. https://doi. org/10.1002/lsm.22775.

137. Zhang Y, Li L, Hua Y, Nunn JM, Dong F, Yanagisawa M, Ren J. Cardiac-specific knockout of ET(A) receptor mitigates low ambient temperature-induced cardiac hypertrophy and contractile dysfunction. J Mol Cell Biol. 2012;4:97-107.

138. Qi Y, Qi Z, Li Z, Wong CK, So C, Lo IC, Huang Y, Yao X, Tsang SY. Role of TRPV1 in the differentiation of mouse embryonic stem cells into cardiomyocytes. PLoS One. 2015;10:e0133211.

139. Ren M, Wang T, Huang L, Ye $X, X v Z$, Ouyang C, Han Z. Role of VR1 in the differentiation of bone marrow-derived mesenchymal stem cells into cardiomyocytes associated with Wnt/beta-catenin signaling. Cardiovasc Ther. 2016;34:482-8.

140. Eisenbergand LM, Eisenberg CA. Wnt signal transduction and the formation of the myocardium. Dev Biol. 2006;293:305-15.

141. Lian X, Hsiao C, Wilson G, Zhu K, Hazeltine LB, Azarin SM, Raval KK, Zhang J, Kamp TJ, Palecek SP. Robust cardiomyocyte differentiation from human pluripotent stem cells via temporal modulation of canonical Wnt signaling. Proc Natl Acad Sci U S A. 2012;109:E1848-57. 
142. Feng C, Zhu J, Zhao L, Lu T, Zhang W, Liu Z, Tian J. Suberoylanilide hydroxamic acid promotes cardiomyocyte differentiation of rat mesenchymal stem cells. Exp Cell Res. 2009;315:3044-51.

143. Li L, Zhu J, Tian J, Liu X, Feng C. A role for Gen5 in cardiomyocyte differentiation of rat mesenchymal stem cells. Mol Cell Biochem. 2010;345:309-16.

144. Liu Z, Li T, Liu Y, Jia Z, Li Y, Zhang C, Chen P, Ma K, Affara N, Zhou C. WNT signaling promotes $\mathrm{Nk} 2.5$ expression and early cardiomyogenesis via downregulation of Hdac1. Biochim Biophys Acta. 2009;1793:300-11.

145. Dovey OM, Foster CT, Cowley SM. Histone deacetylase 1 (HDAC1), but not HDAC2, controls embryonic stem cell differentiation. Proc Natl Acad Sci U S A. 2010;107:8242-7.

146. Lu DF, Wang Y, Su ZZ, Zeng ZH, Xing XW, He ZY, Zhang C. Knockdown of the HDAC1 promotes the directed differentiation of bone mesenchymal stem cells into cardiomyocytes. PLoS One. 2014;9:e92179.

147. Ali D, Alshammari H, Vishnubalaji R, Chalisserry EP, Hamam R, Alfayez M, Kassem M, Aldahmash A, Alajez NM. CUDC-907 promotes bone marrow adipocytic differentiation through inhibition of histone deacetylase and regulation of cell cycle. Stem Cells Dev. 2017;26:353-62.

148. Huang Y, Zheng Y, Jin C, Li X, Jia L, Li W. Long non-coding RNA H19 inhibits adipocyte differentiation of bone marrow mesenchymal stem cells through epigenetic modulation of histone deacetylases. Sci Rep. 2016;6:28897.

149. Fu Y, Zhang $P$, Ge J, Cheng J, Dong W, Yuan H, Du Y, Yang M, Sun R, Jiang $H$, Histone deacetylase 8 suppresses osteogenic differentiation of bone marrow stromal cells by inhibiting histone H3K9 acetylation and RUNX2 activity. Int J Biochem Cell Biol. 2014;54:68-77.

150. Yang G, Tian J, Feng C, Zhao LL, Liu Z, Zhu J. Trichostatin a promotes cardiomyocyte differentiation of rat mesenchymal stem cells after 5-azacytidine induction or during coculture with neonatal cardiomyocytes via a mechanism independent of histone deacetylase inhibition. Cell Transplant. 2012;21:985-96.

151. Labovsky V, Hofer EL, Feldman L, Fernandez Vallone V, Garcia Rivello H, Bayes-Genis A, Hernando Insua A, Levin MJ, Chasseing NA. Cardiomyogenic differentiation of human bone marrow mesenchymal cells: role of cardiac extract from neonatal rat cardiomyocytes. Differentiation. 2010;79:93-101. 